\title{
Ondansetron and Granisetron for prevention of postoperative nausea and vomiting following laparoscopic cholecystectomy
}

\author{
Sabin Gauchan, ' Chitra Thapa, 'Priyanka Shakya, 'Ramesh Bhattarai, ' Sajal Shakya' \\ 'Department of Anesthesia, Nepal Medical College and Teaching Hospital, Jorpati, Kathmandu, Nepal.
}

\section{ABSTRACT}

Introduction: Laparoscopic surgeries are known to be associated with a higher incidence of postoperative nausea and vomiting (PONV). Prophylaxis of PONV is usually achieved with a singledose antiemetic drug administered during the surgical procedure. The aim of this study was to compare the antiemetic efficacy of two different 5-hydroxytryptamine-3 (5HT3) receptor antagonists, ondansetron and granisetron when given prophylactically to patients undergoing laparoscopic cholecystectomy.

Methods: It was a randomized, double blind study, conducted in 90 patients. Patients were divided into two groups: Group A and Group B with 45 patients in each group. Patients in groupA were given 100 microgram $/ \mathrm{kg}$ ondansetron intravenously (IV), and patients in Group B were given 40 microgram $/ \mathrm{kg}$ granisetron. Both the drugs were diluted in $10 \mathrm{ml}$ of $0.9 \% \mathrm{NaCl}$ and were given at the end of surgery. The standard general anesthetic technique was administered to all the patients. Episodes of nausea, retching and vomiting were assessed during the first 24 hours after anesthesia.

Results: There was no statistically significant difference for demographic data and duration of surgery among the two groups ( $P>0.05)$. Evaluated nausea and vomiting scores in the first 3 hours period revealed that each of the drugs had a similar antiemetic effect $(\mathrm{P}>0.05)$. Between 4-12 hours also the episodes of nausea, retching as well as vomiting were statistically insignificant in both the groups. In the last 12 hours, episodes of nausea, retching and vomiting were significantly higher in ondansetron group.

Conclusions: Granisetron, when given prophylactically, resulted in a significantly lower incidence of PONV than ondansetron in the first 24 hours.

Keywords: granisetron; laparoscopic cholecystectomy; ondansetron; postoperative nausea and vomiting.

\section{INTRODUCTION}

Despite various advances in anesthetic and surgical techniques, postoperative nausea and vomiting still remain the most common distressing factor after surgery. ${ }^{1}$ The consequences of PONV may be surgical such as wound dehiscence, disruption of vascular anastomosis or anesthetic like aspiration pneumonitis and electrolyte imbalance. Because of increased nursing care required, delayed discharges from recovery units and unexpected readmissions, PONV causes increased financial burden to the institute. Thus prophylactic

Correspondence: Dr. Sabin Gauchan, Department of Anesthesia, Nepal Medical College and Teaching Hospital, Jorpati, Kathmandu, Nepal; E-mail: sabingauchan@gmail.com, Phone: +977-9851058474. 
Gauchan et al. Comparative study of Ondansetron and Granisetron for prevention of postoperative nausea and vomiting following...

antiemetic therapy is justified in high risk patients.

A number of pharmacological agents like antihistamines, butyro-phenones, dopamine receptor antagonist were used for PONV but they were found to be associated with undesirable side effects such as excessive sedation, hypertension, dry mouth, dysphoria, hallucinations and extra pyramidal symptoms

5HT3 receptor antagonist was introduced in 1991. It belongs to the Cys-loop superfamily of ligand-gated ion channels and is first-line therapy in the prevention of PONV. ${ }^{3}$ Currently available $5-\mathrm{HT} 3$ receptor antagonists are ondansetron and granisetron. Ondansetron was the first $5 \mathrm{HT} 3$ receptor antagonist with a relatively short half-life of three to five hours. Other drugs of this group such as tropisetron, polanosetron, dolasetron, alosetron are still not available in our country.

Granisetron, as compared to ondansetron, has a stronger 5HT3 binding, a longer half-life of 8-9 hours, is more potent and longer actingand has also been found to be very effective for preventing PONV after laparoscopic surgery ${ }^{4}$ with less incidence of side effects. ${ }^{5}$

The aim of this clinical trial was to compare the efficacy of ondansetron $100 \mu \mathrm{gm} / \mathrm{kg}$ IV with that of granisetron $40 \mu \mathrm{gm} / \mathrm{kg}$ IV given at the end of surgery in preventing PONV in patients undergoing laparoscopic cholecystectomy.

\section{METHODS}

After approval from Institutional review committee and obtaining informed written consent from all the patients, ninety ASA I, female patients, aged 2045 years, weighing 40-65 kgs, undergoing elective laparoscopic cholecystectomy were randomly divided into two groups (forty five patients each) - Group A ondansetron and group $B$ granisetron. Patients with history of drug allergy, gastrointestinal disease, smokers, motion sickness and/ or PONV, pregnancy or menstruating, and those who had taken antiemetic medication within last 24 hours were excluded from the study.

Pre anesthetic assessment was done a day before surgery and all the patients were premedicated with tablet diazepam $10 \mathrm{mg}$ orally 12 hour before surgery.

Intravenous access was secured in preoperative preparation room. In the operation theatre routine monitoring devices like pulse oximetry, Noninvasive blood pressure and ECG were attached. The anesthetic regimen and surgical procedures were standardized for all patients.
All the patients received inj. midazolam $0.01 \mathrm{mg} /$ $\mathrm{kg}$ and inj.fentanyl $1.5 \mathrm{microgram} / \mathrm{kg}$ intravenously before induction. Anesthesia was induced with inj. propofol $1.5 \mathrm{mg} / \mathrm{kg}$, muscle relaxation was achieved with inj. vecuronium $0.1 \mathrm{mg} / \mathrm{kg}$. Intubation was done with a $7 \mathrm{~mm}$ internal diameter endotracheal tube and capnography was attached. Ventilation was controlled mechanically so as to keep the end tidal $\mathrm{CO}_{2} 35-40$ $\mathrm{mmHg}$. Maintenance of anesthesia was done with oxygen and 1-2 vol\% isofluorane. Muscle relaxation was maintained by intermittent bolus doses of vecuronium bromide. A nasogastric tube was inserted to make the stomach empty of air and other contents. For laparoscopic surgical procedure, peritoneal cavity was insufflated with carbon dioxide to keep intraabdominal pressure $<12 \mathrm{mmHg}$. At the end of surgery, group A received inj. ondansetron $(100 \mu \mathrm{gm} / \mathrm{kg})$ and group B received inj. granisetron $(40 \mu \mathrm{gm} / \mathrm{kg}$ ), both the study drugs were diluted in normal saline to a total of $10 \mathrm{ml}$ volume and given slowly. The residual neuromuscular block was adequately reversed using intravenous glycopyrrolate $0.01 \mathrm{mg} / \mathrm{kg}$ and neostigmine $0.05 \mathrm{mg} / \mathrm{kg}$. The nasogastric tube was suctioned and removed and subsequently trachea extubated. The recovery time (in minutes) was measured from time isofluorane was switched off until patient responded to simple verbal commands. For postoperative analgesia, diclofenac sodium 75-100 mg intramuscular was given six hourly and as needed. All patients were observed postoperatively by doctors who were unaware of the study drug. Patients were transferred to post anesthesia care unit and blood pressure, heart rate and oxygen saturation were monitored. All episodes of PONV (nausea, retching and vomiting) were recorded by direct questioning for $0-3$ hours in post anesthesia care unit and from 4-12 hours and 12-24 hours in postoperative ward.

Nausea was defined as unpleasant sensation associated with awareness of the urge to vomit. Retching was defined as the labored, spastic, rhythmic contraction of the respiratory muscles without the expulsion of gastric contents. Vomiting was defined as the forceful expulsion of gastric contents from mouth. Complete response (free from emesis) was defined as no PONV and no need for any rescue medication. If there were two or more episodes of PONV during first 24 hours, rescue antiemetic (repeat dose of inj. Granisetron 40 $\mu \mathrm{gm} / \mathrm{kg}$ ) was given.

The result was scored as $0=$ complete response, $1=$ nausea, 2 = retching, $3=$ vomiting.

Any other adverse reactions of drug like headache, dizziness, hypersensitivity if any was also noted in 24 hour study period. 
Data analysis: Continuous variables were reported as mean \pm standard deviation and analyzed using independent sample t-test. Categorical variables were reported as numbers and analyzed using chi - square test. A P $<0.05$ was considered statistically significant.

\section{RESULTS}

Total 90 patients were included in the study. There was no significant difference in age, weight and duration of surgery in two groups.

Table 1. Demographic profile and duration of surgery.

\begin{tabular}{|llll|}
\hline & Group A & Group B & P-value \\
Age (years) & $33.42 \pm$ & $35 \pm 6.49$ & 0.927 \\
& 6.87 & & \\
Weight $(\mathrm{kg})$ & $53.26 \pm$ & $49.64 \pm$ & 0.322 \\
& 7.12 & 11.17 & \\
Duration & $76.46 \pm 22$ & $67 \pm 22.42$ & 0.980 \\
of surgery & & & \\
(minutes) & & & \\
\hline
\end{tabular}

Values are in mean \pm SD.
Incidence of complete response to prophylactic drug during first three hours was $95.5 \%$ in ondansetron group and $100 \%$ in granisetron group. Evaluated nausea and vomiting scores in the first three hours period revealed that both the drugs had a similar antiemetic effect $(P>0.05)$.

Between 4-12 hours, $82.2 \%$ of the patients in ondansetron had complete response, where as in granisetron group $95.5 \%$ of the patients had complete response. But when compared statistically the episodes of nausea, retching and vomiting were insignificant in both the groups $(P=0.092)$

Incidence of complete response to prophylactic drug during $12-24$ hours was $86.66 \%$ in ondansetron group and $95.5 \%$ in granisetron group. However episodes of nausea, retching as well as vomiting were significantly higher in group $A$ than in group $B(P=$ value 0.018$)$.

\begin{tabular}{|c|c|c|c|c|}
\hline & Score & Group A & Group B & P-value \\
\hline \multicolumn{5}{|l|}{$0-3 \mathrm{hrs}$} \\
\hline Complete response & 0 & 43 (95.5\%) & $45(100 \%)$ & \multirow{4}{*}{0.153} \\
\hline Nausea & 1 & 2 & 0 & \\
\hline Retching & 2 & 0 & 0 & \\
\hline Vomiting & 3 & 0 & 0 & \\
\hline \multicolumn{5}{|l|}{ 4-12 hrs } \\
\hline Complete response & 0 & $37(82.22 \%)$ & $43(95.5 \%)$ & \multirow{4}{*}{0.092} \\
\hline Nausea & 1 & 2 & 2 & \\
\hline Retching & 2 & 2 & 0 & \\
\hline Vomiting & 3 & 4 & 0 & \\
\hline \multicolumn{5}{|l|}{$12-24 \mathrm{hrs}$} \\
\hline Complete response & 0 & $39(86.66 \%)$ & $43(95.5 \%)$ & \multirow{4}{*}{0.018} \\
\hline Nausea & 1 & 0 & 2 & \\
\hline Retching & 2 & 3 & 0 & \\
\hline Vomiting & 3 & 3 & 0 & \\
\hline
\end{tabular}

\section{DISCUSSION}

The incidence and intensity of the PONV has decreased because of the identification of factors that are known to cause the problem. Still PONV occur with unacceptable frequency and is referred to as "the big little problem". ${ }^{2}$ The prevalence of PONV in patients undergoing laparoscopic cholecystectomy has been reported to be $46-72 \% .^{6}$ The cause of PONV is attributed to pneumoperitoneum causing stimulation of mechanoreceptors in the gut and absorbed $\mathrm{CO}_{2}$ stimulating the nociceptors in the brain. The occurrence of PONV also depends upon a variety of other factors including patient characteristic, duration of surgery and anesthetic technique. In our study the factors that would have contributed to nausea and vomiting may be laparoscopic surgery, female gender, use of opioid and volatile agent. Incidence of PONV is three times 
Gauchan et al. Comparative study of Ondansetron and Granisetron for prevention of postoperative nausea and vomiting following...

higher in females than in males. ${ }^{7}$ Because of difference in the risk of PONV among males and females, only females were selected in the study. Other factors such as age, weight, duration of surgery, and anesthetic technique were comparable in both the groups. Non opioids analgesics were used for postoperative pain. So the difference in complete response between the groups can be attributed to the study drug alone.The timing of prophylactic administration of antiemetic has been found to have a significant effect on its efficacy in preventing severe PONV.8,9 Tang et al, found a higher percentage of satisfied patients (90\% vs $67 \%$ ) when ondansetron was administered near the end of surgery. ${ }^{9}$ It is stated that this makes the drug to be effective for longer time. Similar results were found in study done by Janknegt ${ }^{10}$ and Sinha. ${ }^{11}$ So we chose to administer study drug just prior to the end of surgery.

Studies done by Paxton ${ }^{12}$ and Fujii $^{13}$ state that nausea and vomiting occur more commonly in first six hours post operatively.

In our study there was no vomiting in first three hours in both the groups, there were two patients in ondansetron group who experienced nausea but it was statistically insignificant, which suggest that both the drugs are having good control over PONV in the first three hours. In the next nine hours though the episodes of retching and vomiting were higher in ondansetron group than in granisetron group it was statistically insignificant.

After 12 hours, episodes of nausea, retching and vomiting were significantly higher in ondansetron group than in granisetron group.
In this study ondansetron though effectively controlled PONV for upto $12 \mathrm{hrs}$ postoperatively failed to do so after 12 hrs, whereas PONV was significantly reduced by granisetron up to first 24 hours postoperatively.

Vishal Gupta et $\mathrm{al}^{14}$ in 2008 compared effects of prophylactic granisetron and ondansetron following laparoscopic cholecystectomy and found that granisetron was more effective in controlling PONV than ondansetron. Similarly Oksuz H et al ${ }^{15}$ in 2007 compared ondansetron with granisetron as a prophylactic anti emetic and concluded granisetron to be more effective than ondansetron.

Though no CNS effects were seen in our study, ondansetron is said to be associated with a higher incidence and severity of certain CNS side effects compared with other $5 \mathrm{HT} 3$ antagonist. ${ }^{16} \mathrm{~A}$ Chidambaram et $\mathrm{al}^{17}$ in their study have reported significantly higher incidence of headache $(20 \%)$ in ondansetron group than in Granisetron (12\%).

Aspinall and Goodman ${ }^{18}$ have suggested that if active drugs are available, placebo-controlled trials may be unethical because PONV are very much distressing after laparoscopic surgery. So we decided not to include a control group, receiving placebo in our study.

\section{CONCLUSIONS}

Hence, this study concluded that prophylactic therapy with granisetron is more effective than prophylactic therapy with ondansetron for prevention of PONV following laparoscopic cholecystectomy in the first 24 hours.

\section{REFERENCES}

1. Gold BS, Kitz PS, Lecky JA. Unanticipated admission to the hospital following ambulatory surgery. JAMA. 1989;262:3008-10.

2. Watcha MF, White PF. Postoperative nausea and vomiting: its etiology, treatment and prevention. Anesthesiology. 1992;77:162-84.

3. Habib AS, Gan TJ. Evidence-based management of postoperative nausea and vomiting: A review. Can J Anaesth. 2004;51:326-41.

4. Peyez EA, Hasketh P, Sandback J, Chawla S.Comparison of single dose oral Granisetron Vs IV Ondansetron in the prevention of nausea and vomiting induced by moderately emetogenic chemotherapy: A multicentre double blind randomized parallel study. J Clin Oncol. 1981;6:754-60.
5. Toyooka H, Tanaka H. Oral granisetron prevents postoperative vomiting in children. BJA. 1998;81:390-99.

6. Wang JJ, Ho ST, Liu YH, Lee SC, Liu YC, Liao YC, et al. Dexamethasone reduces nausea and vomiting after laparoscopic cholecystectomy. Br J Anaesth. 1999;83:772-5.

7. Bondner $\mathrm{M}$, Honkovaara P. Nausea and vomiting after gynaecological laparoscopy depends upon the phase of the menstrual cycle. Can J Anaesthesia. 1991;38:876-87.

8. Sun R, Klein KW, White PF. The effect of timing of ondansetron administration in outpatient undergoing otolaryngologic surgery. Anesth Analg. 1997;84:331-6.

9. Tang J, Wang B, White PF, et al. The effect of timing of ondansetron administration on its efficacy, cost effectiveness, and cost benefits as a prophylactic antiemetic in the ambulatory setting. Anesth Analg. 1998;86:274-82. 
Gauchan et al. Comparative study of Ondansetron and Granisetron for prevention of postoperative nausea and vomiting following...

10. Janknegt R. Clinical efficacy of antiemetic following surgery. Anaesthesia. 1999;54:1054-68.

11. Sinha PK, Sushil P. Ondansetron in prophylaxis of postoperative nausea and vomiting in patients undergoing breast surgery: A placebo-controlled double blind study. J Ind Med. Assoc. 2004;102.

12. Paxton DL, McKay CA. Prevention of nausea and vomiting after day care gynaecological laproscopy. Anaesthesia. 1995;50:403-46.

13. Fujii $Y$, Tanaka H, Toyooka H. Granisetron reduces vomiting after strabismus surgery and tonsillectomy in children. Can J Anaesth. 1996;43:35-8.

14. Gupta V, Wakhloo R, Mehta A, Gupta SD. Prophylactic antiemetic therapy with ondansetron, granisetron and metoclopramide in patients undergoing laparoscopic cholecystectomy under general anesthesia. JK Science. 2008;10(2):74-7.
15. Oksuz H, Zencirci B, Ezberci M.Comparison of the effectiveness of metoclopramide, ondansetron, and granisetron on the prevention of nausea and vomiting after laparoscopic cholecystectomy. J Laparoendosc Adv Surg Tech A. 2007 Dec;17(6):803-8.

16. White PF, Tang J, Hamza MA, Ogunnaike B, et al. The use of oral granisetron versus iv ondansetron for antiemetic prophylaxis in patients undergoing laparoscopic surgeries: the effect on emetic symptoms and quality of recovery. AnesthAnalg. 2006 May;102(5):1387-93.

17. Chidambaram A , Bylappa K, Somasekaram P. A Comparative Study Of Ondansetron And Granisetron For Prevention Of Nausea And Vomiting Following Laparoscopic Surgeries. The Internet Journal of Anesthesiology. 2011;29(1).

18. Aspinall RL, Goodman NW. Denial of effective treatment and poor quality of clinical information in placebo controlled trials of ondansetron for postoperative nausea and vomiting: a review of published trials. BMJ. 1995;311:844-6. 